Int. J. Dev. Biol. 64: 433-443 (2020)

https://doi.org/10.1387/ijdb.200078gc

\title{
PuraMatrix allows differentiation of a broad repertoire of neural and mesenchymal phenotypes from trunk neural crest
}

\author{
CLARISSA R. TAUFER ${ }^{1,2}$, MONICA A. RODRIGUES-DA-SILVA ${ }^{2}$ and GIORDANO W. CALLONI*,2 \\ ${ }^{1}$ Programa de Pós-graduação em Biologia Celular e do Desenvolvimento and ${ }^{2}$ Laboratório de Plasticidade e Diferenciação \\ de Células da Crista Neural, Departamento de Biologia Celular, Embriologia e Genética, Centro de Ciências Biológicas, \\ Universidade Federal de Santa Catarina, Campus Universitário - Trindade, Florianópolis, S.C., Brazil
}

\begin{abstract}
The neural crest (NC) is a transitory embryonic structure of vertebrates that gives rise to an astonishing variety of derivatives, encompassing both neural and mesenchymal cell types. Neural crest cells (NCCs) are an excellent model to study how environmental factors modulate features such as cell multipotentiality and differentiation. Tests with multifunctional substrates that allow NCCs to express their full potential, while promoting cell subcloning, are needed to advance knowledge about NCC self-renewal and to foster future biotechnological approaches. Here we show that a self-assembled peptide named PuraMatrix ${ }^{\mathrm{TM}}$ is an excellent substrate that allows the differentiation of NCCs based on the identification of seven different cell types. Depending on the PuraMatrix ${ }^{\mathrm{TM}}$ concentration employed, different frequencies and quantities of a given cell type were obtained. It is noteworthy that an enormous quantity and diversity of mesenchymal phenotypes, such as chondrocytes, could be observed. The quantity of adipocytes and osteocytes also increased with the use of mesenchymal differentiation factors (MDF), but PuraMatrix ${ }^{\mathrm{TM}}$ alone can support the appearance of these mesenchymal cell types. PuraMatrix ${ }^{\mathrm{TM}}$ will promote advances in studies related to multipotentiality, self-renewal and control of NCC differentiation, since it is an extremely simple and versatile material which can be employed for both in vivo and in vitro experiments.
\end{abstract}

KEY WORDS: PuraMatrix, RADA16, trunk neural crest, neural, mesenchymal, skeletogenic

\section{Introduction}

Neural Crest Cells (NCCs) are multipotent cells able to give rise to an astonishing variety of cell types. This heterogeneity is outstanding since unrelated tissues, such as the peripheral nervous system and head skeleton of vertebrates, are mostly derived from embryonic NCCs (Dupin et al., 2018). Both in vivo (Baggiolini et al., 2015; Bronner-Fraser and Fraser, 1988) and in vitro experiments (Calloni et al., 2007; Calloni et al., 2009; da Costa et al., 2018) indicate that most NCCs are multipotent and not fate-restricted after emerging from the neural tube. Thus, the final identities of NCCs are adopted during migration and settlement at the final target tissues. Environmental cues, i.e., growth factors and extracellular matrix, present in, or emanating from, the surrounding environment, drive NCCs differentiation (Dupin et al., 2018). Much is known about growth factors and morphogens guiding NCCs differentiation (Shah and Anderson, 1997; Paratore et al., 2002). However, less is known about how specific substrates or extracellular matrices act on NCC differentiation.
The cell types obtained from trunk neural crest cells (TNCCs) cultured on plastic culture dishes are restricted to glial cells, smooth muscle cells, melanocytes and some few neurons (Bittencourt et al., 2013). Plastic culture surfaces coated with commercially available purified extracellular matrices, such as fibronectin, laminin, or collagens I and IV, are easy to manipulate and enable the creation of controlled substrate environments (Loring et al., 1982; Perris et al., 1993). For example, fibronectin has been effective in selecting specific NCCs progenitors endowed with smooth muscle differentiation potential (Costa-Silva et al., 2009). Studies like this have gained insight into the importance of fibronectin for correct heart development, given that cardiac NCCs contribute extensively to this tissue (George et al., 1993).

\footnotetext{
Abbreviations used in this paper: $\alpha$-SMA, $\alpha$-smooth muscle actin; ALP, alkaline phosphatase; AR, alizarin red; CS, chondroitin sulfate; DAPI, 4'-6-diamidino-2-fenilindol; ECM, extracellular matrix; HNK1, human natural killer 1; MDF, mesenquimal diferentiation factor; NC, neural crest; NCG, neural crest cell; PM, PuraMatrix; $\mathrm{TH}$, tyrosine hydroxylase; TNCC, trunk neural crest cell.
}

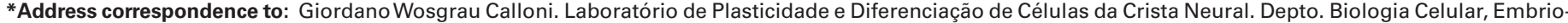

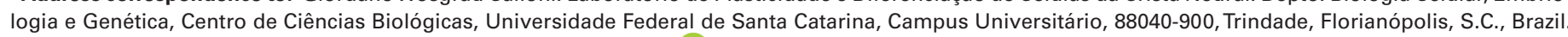
Phone: (+55) 48-37214581. E-mail adress: giordano.calloni@ ufsc.br - iD) https://orcid.org/0000-0003-3954-0808
}

Submitted: 1 April, 2020; Accepted: 14 July, 2020.

ISSN: Online 1696-3547, Print 0214-6282 
However, even isolated specific extracellular matrix (ECM) molecules do not allow expression of the full potential of NCCs, like neurons and chondrocytes. To circumvent this limitation, monolayers of mouse embryonic cells (3T3) were adopted as substrate to perform NCCs cultures (Baroffio et al., 1988). Importantly, much of what is currently known about multipotentiality and differentiation potential of avian NCC s comes from studies using 3T3 feeder-layers as substrate (Baroffio et al., 1988; Baroffio et al., 1991; Trentin et al., 2004; Calloni et al., 2007; Calloni et al., 2009; da Costa et al., 2018). However, as a complex living substrate, 3T3 prevents subcloning experiments from being carried out, greatly restricting in vitro studies. To overcome such drawbacks, we tested a substrate composed of the basement membrane derived from a rat sarcoma and commercially available (Matrigel ${ }^{\mathrm{TM}}$ ) (Kleinman and Martin, 2005). Matrigel ${ }^{\mathrm{TM}}$ can be disassembled, allowing subcloning experiments. This substrate proved to support the differentiation of the main TNCCs types, such as glial cells, neurons and melanocytes. Also a high frequency (over $80 \%$ of cultures) containing chondrocytes was observed (Ramos-Hryb et al., 2013).

However, Matrigel ${ }^{\mathrm{TM}}$ also involves problems, such as different concentrations of ECM molecules and the presence of several known and unknown growth factors which promote variations from batch to batch (Kleinman and Martin, 2005). One solution is to mix several batches in an attempt to "homogenize" the differences among batches, but this makes Matrigel ${ }^{\mathrm{TM}}$ impractical to use and expensive (Ramos-Hryb et al., 2013). Moreover, since Matrigel ${ }^{\mathrm{TM}}$ is removed from rat osteosarcoma, it cannot be used as a substrate in future cell therapies. Thus, all these concerns prompted us to search for other substrates that can overcome all these issues.

We envisioned that a class of self-assembled peptides developed in the 90 s by Dr. Zhang could address the challenge. One of them, PuraMatrix $^{\text {TM }}(\mathrm{PM})$ is a 16 amino acid synthetic peptide formed by repeated sequences of arginine-alanine-aspartic acid-alanine, also described as (RADA) ${ }_{4}$ or RADA16-I (Zhang et al., 1995). Since PM consists of amino acids ( $1 \% \mathrm{w} / \mathrm{v})$ and $99 \%$ water, it is an extremely pure matrix, free from growth factors and any kind of animal matter. When in contact with salt solutions, PM peptides self-assemble spontaneously, forming fiber sizes 7 to $10 \mathrm{~nm}$ in diameter, very similar to natural ECM of 5-10 nm. Pore size ranges from 50 to $400 \mathrm{~nm}$, varying according to its concentration in water (Zhang et al., 2005). PM has been used as substrate or scaffold to perform cultures of several cell types, but no study has previously tested PM using embryonic NCCs.

Here, we show, for the first time, that PM allows the survival, proliferation and differentiation of a vast array of cell types derived from TNCCs. Our data show that PM is a new substrate to culture embryonic NCCs and that it helps to foster future studies related to NCCs multipotentiality, self-renewal and differentiation, as well as envision biotechnological approaches since NCCs exhibit stem cell properties that have been found in several adult tissues.

\section{Experimental Procedures}

\section{Ethical concerns}

The animal protocol used in this study was approved by the Ethics Committee on Animal Use of the Federal University of Santa Catarina (CEUA/UFSC) under the protocol $n^{\circ} 7224130916$ (ID 000289).

\section{NCC cultures}

TNCCs were isolated from explanted neural tubes at the tho- racic level (last 10 somites) from quail embryos at 18-24 somite stage. The explanted neural tubes were seeded on a $35 \mathrm{~mm}$ plastic dish (Corning ${ }^{\circledR}$ ) with "basic medium" consisting of alpha-modified minimum essential medium (a-MEM, Invitrogen $®$ ), 10\% fetal bovine serum (FBS, Invitrogen $($ ) ) and $2 \%$ chicken embryo extract. After 15 hours of primary culture, the neural tubes were discarded under microscopic control with tungsten needles, and the migrated TNCCs were harvested with trypsin $0.05 \%$ (Invitrogen ${ }^{\circledR}$ ) to perform secondary cultures.

Isolated TNCCs were seeded in 96-well plates (around 400 cells/ well) previously coated with $20 \mu \mathrm{L}$ of PuraMatrix ${ }^{\mathrm{TM}}$ (Corning $\left.{ }^{\circledR}\right)$ pure (1\%) or diluted in Milli-Q water at $0.15 \%, 0.25 \%$, and $0.5 \%$ strictly, as described by the manufacturer's guidelines. TNCCs were maintained in "basic medium" through the time of secondary cultures, i.e., 14 and 21 days. In 21-day experiments 50 cells/well were seeded (instead of 400 cells/well) in order to avoid detachment of cells from the wells surface around day 18. On the seventh day of secondary culture, part of the cultures was supplemented with hormones and/ or growth factors added to the "basic medium" in order to stimulate osteogenic and adipogenic differentiation. This medium was similar to a medium previously employed, called MDF (for Mesenchymal Differentiation Factors) (Coelho-Aguiar et al., 2013). MDF was composed of $\beta$-glycerol phosphate $(5 \mathrm{mM})$; ascorbic acid $(25 \mathrm{mg} /$ $\mathrm{ml})$; dexamethasone $(0.05 \mathrm{mM})$; insulin $(2.5 \mathrm{mg} / \mathrm{ml})$; indomethacin $(100 \mathrm{mM})$ and isobutylmethylxanthine $(0.5 \mathrm{mM})$ (all from Sigma $\left.{ }^{\circledR}\right)$. Cells were maintained for 14 or 21 days at $37^{\circ} \mathrm{C}$ in a humidified $5 \%$ and $\mathrm{CO}_{2} 95 \%$ air atmosphere, with medium replaced every 3 days.

\section{Live/dead assay}

Viability of NCCs on PM was measured by LIVE/DEAD assay (Invitrogen $®$ ) used strictly according to manufacturer's instructions. Live/Dead cells were visualized by fluorescence microscopy (Olympus IX71), and quantitative data were obtained by manually counting random and non-overlapping microscopic fields at 3, 5 and 7 days of culture. All PuraMatrix ${ }^{\mathrm{TM}}$ concentrations described above were tested.

\section{Phenotypic analysis}

At 14 or 21 days of secondary cultures, TNCCs were fixed with $4 \%$ paraformaldehyde for $40 \mathrm{~min}$. The analysis of distinct phenotypes was performed employing different specific antibodies and/ or staining. Chondrocytes were first observed as three-dimensional cell aggregates under phase-contrast microscopy and then detected by immunofluorescence to Chondroitin Sulfate (CS) (1:1600; clone CS56 Sigma $\left.{ }^{\circledR}\right)$. Cartilage matrix was also evidenced by Alcian Blue (Sigma $\left.{ }^{\circledR}\right)$ staining $(2 \%$ in $\mathrm{HCl} 0.1 \mathrm{M})$ for $40 \mathrm{~min}$. Then excess staining was washed out by three rinses in Milli- $Q$ water.

To specifically detect cells of bone lineage we first performed immunocytochemistry reactions employing the monoclonal antibody SB-5, as developed by Arnold Caplan between the 1980s and 1990s (Bruder and Caplan, 1990). Dr. Caplan generously donated some aliquots of this antibody to our research group. The cultures were maintained overnight with $50 \mu \mathrm{l} \mathrm{SB}-5$ conditioned media antibody. After PBS washing of primary antibody, the cultures were incubated for 1 hour at room temperature with $50 \mu$ of specific IgM secondary isotype antibody (1:100; Alexa 488; Invitrogen $®)$. For identification of bone mineralization, two markers were initially employed: the early stage marker Alkaline Phosphatase (ALP) (Sigma ${ }^{\circledR} 85 \mathrm{~L} 2$ kit), the activity of which is important to start bone mineralization, and the stain Alizarin Red (AR) which detects calcific deposition (matrix 
mineralization) by osteogenic cells. To prepare the ALP solution, a Fast-blue RR salt capsule was diluted in $48 \mathrm{ml}$ of distilled water at room temperature. Culture wells received $50 \mu \mathrm{l}$ of the ALP staining solution that remained protected from direct light for $30 \mathrm{~min}$. Another set of cultures received $50 \mu \mathrm{l}$ of $2 \%$ AR that was maintained for 10 $\min$. After the respective staining times, the cultures were washed with distilled water.

Adipocytes were visualized through triglyceride lipid accumulation employing Oil Red O staining in which a stock solution of Oil Red $\mathrm{O}$ (Sigma®) at $0.5 \%$ in isopropanol was diluted 6:4 (vol:vol) in $\mathrm{H} 2 \mathrm{O}$ and filtered before application to the cultures for $30 \mathrm{~min}$.

The other NC phenotypes were detected strictly as previously described by Ramos-Hryb (2013), i.e., glial cells detected by HNK1 antibody, tyrosine hydroxylase (TH) for catecholaminergic (all undiluted hybridoma supernatants), and $\alpha$-smooth muscle actin ( $\alpha$ SMA; 1:400, Sigma ${ }^{\circledR}$ ) for myofibroblasts/smooth muscle cells. Specific secondary antibodies, Alexa-488 and Alexa-594, were all from Invitrogen $\AA$. Pigment cells were recognized by the simple presence of melanin. Cell nuclei were stained with 4',6-Diamidino2-Phenylindole(DAPI). Fluorescence wasobserved with an Olympus IX71 microscope.

\section{Statistical analysis}

Cell viability was calculated by one-way ANOVA with the Tukey's Post-test. Results were expressed as Mean + SEM and considered significant with $\mathrm{p}$-value $\leq 0.05$.

Phenotypic analysis was performed by comparing the sum of positive culture wells (absolute frequencies) of a given phenotype by chi-square test $\left(x^{2}\right)$. Two kinds of comparisons were performed:a) the effect of different PM concentrations on the frequency of appearance of a given phenotype, and $b$ ) the effect of MDF on the frequency of appearance of a given phenotype, in this case always comparing against the untreated MDF group at the same PM concentration. Results were expressed as the percentage of positive wells for a given phenotype and considered significant with $p$-value $\leq 0.01$.

Since the amount of some cell types per well was enormous, we merely estimated their quantity to give an order of magnitude, which can be observed in Tables 1 and 2. All statistical analyses described were performed with Prism 6 (GraphPad® Prism. Inc., USA).

\section{Results and Discussion}

\section{PuraMatrix ${ }^{T M}$ supports the differentiation of neural and melanocytic phenotypes derived from Trunk Neural Crest Cells}

First, we tested TNCCs viability cultured at four different PM concentrations ( $1 \%, 0.5 \%, 0.25 \%$ and $0.15 \%)$.

On the $3^{\text {rd }}$ day of culture the number of living cells was higher in TNCCs cultures performed on PM at $0.15 \%$ and $0.25 \%$, compared to $\mathrm{PM}$ at $0.5 \%$ and especially to PM at $1 \%$ (Fig. 1A). The number of dead cells was not statistically different among all PM concen-
A

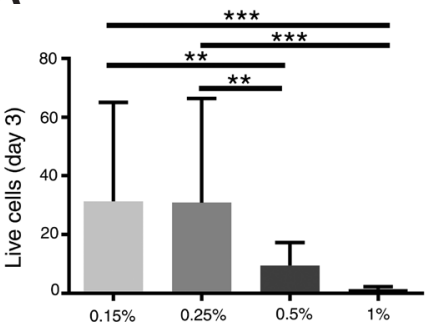

1. PuraMatrix ${ }^{\mathrm{TM}}$ (PM) supports survival and proliferation of trunk neural crest cells (TNCCs). Number of live $(\mathbf{A}, \mathbf{D}, \mathbf{G})$ and dead $(\mathbf{B}, \mathbf{E}, \mathbf{H})$ cells in $d 3, d 5$ and $d 7$ TNCCs cultures, grown on different PM concentrations with or without mesenchymal differentiation factors (see Materials and Methods for details). Data obtained from counting 30 random microscopic fields from three independent experiments (to d3 and d5) and from 20 random microscopic fields from two independent experiments (to d7). All analysis performed by one-way ANOVA with the Tukey's Post-test. Results were expressed as Mean + SEM and considered significant where ${ }^{*} P<0.05 ;{ }^{*} P<0.01$ and *** $P<0.001$. Graphics in $(\mathbf{C}, \mathbf{F}, \mathbf{I})$ express the ratio between live and dead cells in the total cell population in each time point and are expressed as percentage (\%). [ ] = concentration.
[ ] PuraMatrix ${ }^{\mathrm{TM}}$

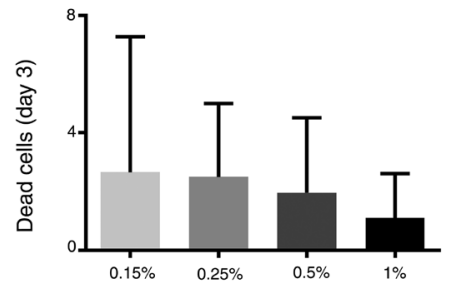

[ ] PuraMatrix ${ }^{\mathrm{TM}}$

E

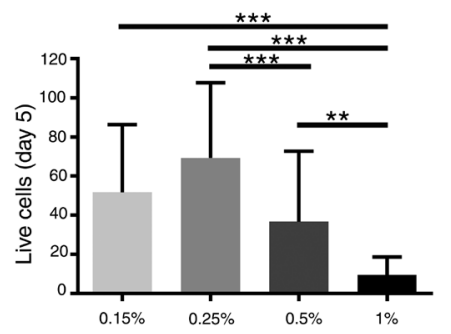

[ ] PuraMatrix ${ }^{\mathrm{TM}}$

G

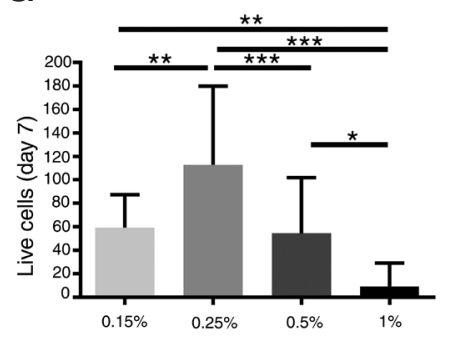

[ ] PuraMatrix ${ }^{\mathrm{TM}}$

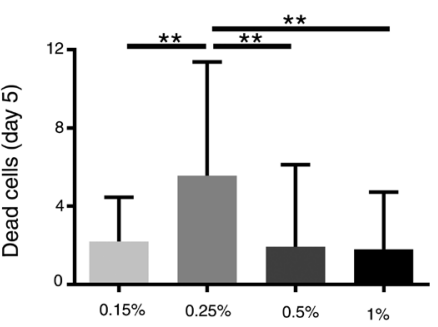

[ ] PuraMatrix ${ }^{\mathrm{TM}}$
B

C

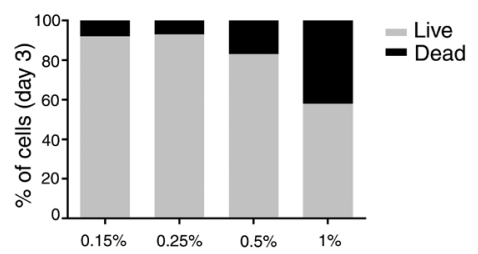

[ ] PuraMatrix ${ }^{\mathrm{TM}}$

F

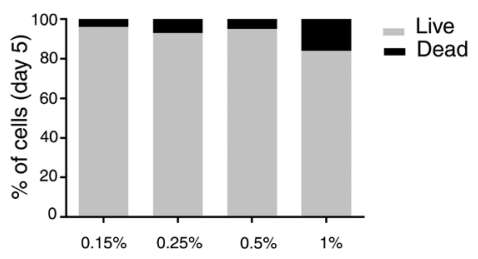

[ ] PuraMatrix ${ }^{\mathrm{TM}}$
H

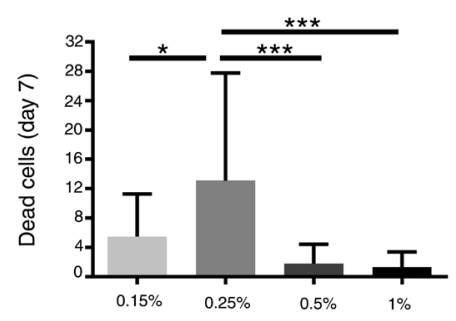

[ ] PuraMatrix ${ }^{\mathrm{TM}}$

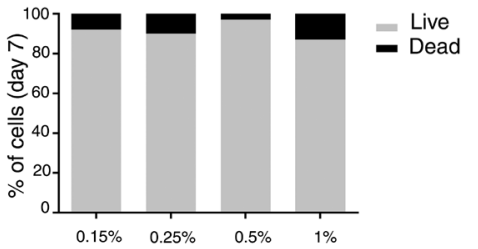

[ ] PuraMatrix ${ }^{\mathrm{TM}}$ 
trations (Fig. 1B). However, strong differences were detected when taking into account the proportions of dead cells compared to the total of living cell population. At PM 1\%, dead cells corresponded to $42 \%$ of the total cell population. The proportion of dead cells decreases to $17 \%$ in $\mathrm{PM}$ at $0.5 \%$ and to less than $10 \%$ at PM $0.25 \%$ and $0.5 \%$ (Fig. $1 \mathrm{C}$ ).

On the $5^{\text {th }}$ day of culture the number of living cells was higher in TNCCs cultures performed on PM at $0.25 \%$, compared to PM at $0.5 \%$ and $1 \%$. PM at $0.15 \%$ and $0.5 \%$ also exhibited more living cells compared to PM 1\% (Fig. 1D). However, as the number of dead cells was higher in PM at $0.25 \%$, compared to PM at $0.15 \%$ and $0.5 \%$, the proportion of living cells was very similar (around 95\%) among all these concentrations (Fig. 1E). The only exception was $\mathrm{PM}$ at $1 \%$, which exhibited proportionally the double of dead cells (16\%), compared to PM at $0.25 \%$ (Fig. 1F).

Finally, on the $7^{\text {th }}$ day of culture the number of living cells was higher in PM at $0.25 \%$, compared to all other PM concentrations (Fig. 1G). The number of dead cells was also higher at this concentration, making the proportion of living cells very similar among the PM concentrations (more than 90\%) (Fig. $1 \mathrm{H}$ and 11). Again, the only exception was PM at $1 \%$, which exhibited proportionally the double of dead cells (16\%), compared to PM at $0.25 \%$ (Fig. 1I).

Considering that $\mathrm{PM}$ at $1 \%$ presented higher proportion of dead cells compared to all the other PM concentrations and did not promote a significant expansion of the initial TNCCs population, we pursued our studies with PM in concentrations of $0.5 \%, 0.25 \%$ and $0.15 \%$. The three different concentrations tested allowed the differentiation of glial cells, adrenergic cells and melanocytes (Fig. 2). A cocktail of growth factors and hormones (MDF see Materials and Methods) was added from day 7 to day 14. Even considering that MDF acts by stimulating adipocytic and osteogenic differentiation, we also search for possible influences of MDF in neural and melanocytic phenotypes.

Glial cells were present in almost $95 \%$ of cultures at $0.15 \%$ and $0.25 \%$ PM concentrations (Fig. 2A). However, this percentage dropped to $60 \%$ at $0.5 \%$ PM concentration (Fig. 2A). The number of glial cells per well was also higher in PM at $0.15 \%$ and $0.25 \%$ compared to PM $0.5 \%$ concentration (Table $1 \mathrm{~A}$ ). Treatment with MDF diminished both the number and the frequency of glial cells appearing in all PM concentrations tested (Table 1 and Fig. 2A, respectively). Taken together, these data suggest that the lowest PM concentrations are better for glial

\section{TABLE 1}

\section{ESTIMATED AMOUNTS OF GLIAL CELLS, NEURONS AND MELANOCYTES PER WELL IN TNCCS CULTURED ON PURAMATRIX ${ }^{\mathrm{TM}}$ (PM)}

\begin{tabular}{lcccccc} 
& \multicolumn{2}{c}{ Glial cells } & \multicolumn{2}{c}{ Neurons } & \multicolumn{2}{c}{ Melanocytes } \\
\hline[] $\mathrm{PM}^{\mathrm{TM}}$ & $-\mathrm{MDF}$ & $+\mathrm{MDF}$ & $-\mathrm{MDF}$ & $+\mathrm{MDF}$ & $-\mathrm{MDF}$ & + MDF \\
$0.15 \%$ & $* *$ & $*$ & $*$ & $* \uparrow$ & $*$ & $*$ \\
$0.25 \%$ & $* *$ & $*$ & $*$ & $* \uparrow$ & $*$ & $*$ \\
$0.5 \%$ & $*$ & $* \downarrow$ & $*$ & $* \uparrow$ & $*$ & $*$ \\
\hline
\end{tabular}

Four main groups classified according to the estimated quantity of each phenotype: Small $\left({ }^{\star}\right)$, medium $\left({ }^{\star *}\right)$, large $\left({ }^{\star \star \star}\right)$ and very large quantity $\left({ }^{* * \star *}\right)$. ${ }^{*}$ Small (present in up to $25 \%$ of the well), ${ }^{\star \star}$ medium (present in up to $50 \%$ of the well), ${ }^{\star \star *}$ large (present in up to $75 \%$ of the well) and ${ }^{\star \star \star \star}$ very large (present in up to $100 \%$ of the well). The arrows indicate a decreasing (down arrow) or increasing (up arrow) tendency in cell number, comparing MDF-treated to untreated conditions. [ ] = concentration. phenotype differentiation and that treatment with MDF disrupts glial development. The morphology of the majority of glial cells was flat and scattered at $0.15 \%$ in both control and MDF-treated cultures (Fig. 2B). At $0.25 \%$ and $0.5 \%$ in treated and untreated cultures, most of cells were more elongated, exhibiting a fusiform morphology and displaying long projections which we may suggest to be filopodia (Fig. 2C). However, it is important to note that none of these morphologies was detected exclusively in a given concentration of PM, but rather a mixture of cells exhibiting different morphologies was the norm.

A previous study demonstrated that PM $0.25 \%$ promoted adhesion, survival and proliferation in vivo and in vitro of Schwann cells obtained from sciatic nerves of human fetuses (Moradi et al., 2012). PM at $0.10 \%, 0.15 \%$ and $0.25 \%$ concentrations also allowed the differentiation of glial cells derived from human embryonic stem cells (Ylä-Outinen et al., 2014). More recently, $\mathrm{PM}$ at $0.10 \%$ has been associated with electrospinning of Poly (lactic-co-glycolic acid) forming peptide cospun scaffolds. In this association, PM exerted a biomimetic cell recognition motif towards functional proliferation of rat Schwann cell line 96 (Nune et al., 2019). Our data demonstrate that PM allows the differentiation of glial cells from undifferentiated TNCCs, opening the possibility of future studies related to stem cell therapy.

Regarding adrenergic cells, the percentage of wells exhibiting neurons decreases proportionally at increased PM concentrations (Fig. 2D). Although not statistically significant, MDF promoted an increase in the percentage of wells exhibiting $\mathrm{TH}^{+}$cells compared to untreated wells at $0.25 \%$ and, especially, at $0.5 \%$ PM concentration (Fig. 2D). Moreover, the number of $\mathrm{TH}^{+}$cells was slightly elevated upon MDF treatment (Table 1 and Fig. 2E vs. $2 \mathrm{~F})$. These data show that lower PM concentrations $(0.15 \%$ and $0.25 \%$ ) are better for neural development and that MDF does not disrupt neuronal differentiation. The morphology of the neurons remained very similar among all conditions analyzed (Fig. 2 E-F). Our data agree with a previous work showing that a mixture of PM (at the same concentrations herein tested: $0.15 \%$, $0.25 \%, 0.5 \%$ ) with laminin allowed the differentiation of human neural progenitor cell line (ReNcell) to $\beta$-TubulinIII+ and to $\mathrm{TH}^{+}$ cells. Only at the concentration of $0.5 \%$ was the hydrogel shown to be adverse to $\mathrm{TH}^{+}$cells, as the number of these neurons was reduced (Ortinau et al., 2010). Another study demonstrated that PC12 cells exhibited the longest neurites when cultured at $0.25 \%$ PM compared to $0.5 \%$ and $1 \%$ concentration (Kaneko and Sankai, 2014). PM (at $0.25 \%$ ) was also shown to be a better substrate compared to Matrigel ${ }^{\mathrm{TM}}$ by supporting the survival, migration and differentiation of fetal human neural stem cells (hNSCs) (Thonhoff et al., 2008). On the other hand, we did not find any difference in the frequency of appearance of neuronal phenotype from TNCCs cultivated on PM in comparison to our previous work employing Matrigel ${ }^{\mathrm{TM}}$ (Ramos-Hryb et al., 2013). More recently, Jahan-Abad et al., (2018) cultivated hNSCs cells derived from epileptic human brain (hNS/PCs) in PM. Using a rat model of traumatic brain injury (TBI), they transplanted the hNS/PCs seeded in PM at $0.15 \%$. The cells survived, migrated and differentiated into neurons, microglia and astrocytes in the immediate vicinity of the injured cerebral cortex. Moreover, TBI rats that received $\mathrm{hNS} / \mathrm{PC}$ soaked in $\mathrm{PM}$ displayed improved functional recovery, decreased lesion volume, inhibited neuroinflammation and reduced reactive gliosis at the injury (Jahanbazi 


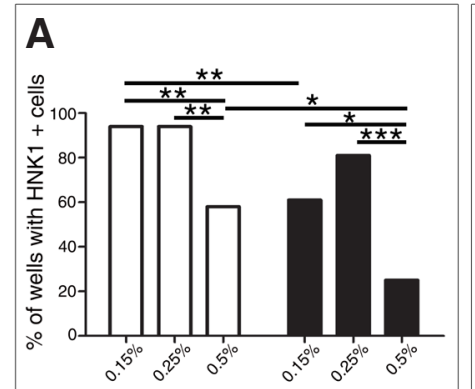

B

[ ] PuraMatrix ${ }^{\mathrm{TM}}$

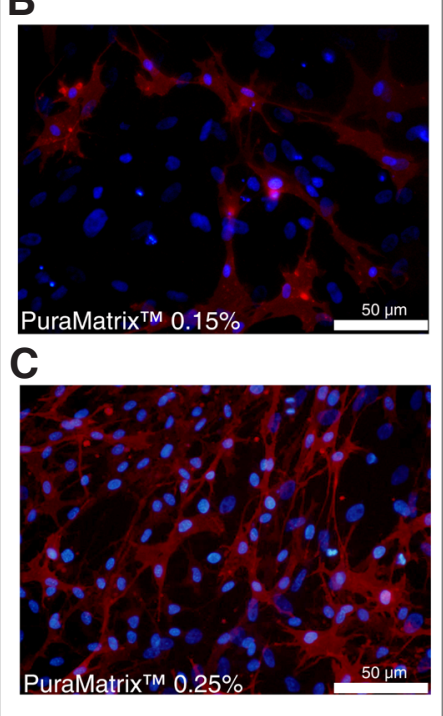

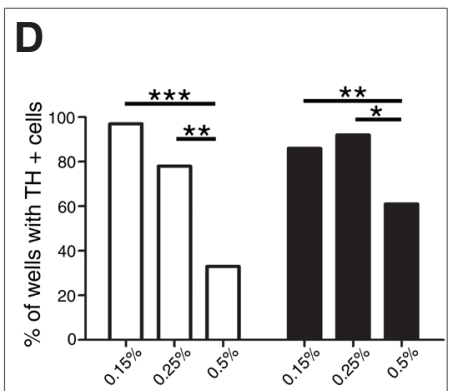

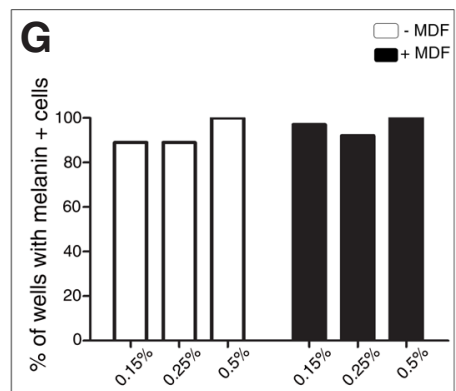

[ ] PuraMatrix ${ }^{\mathrm{TM}}$

E

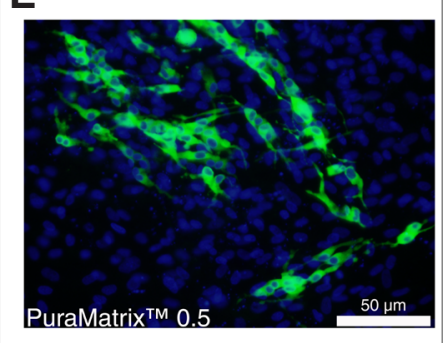

$F$

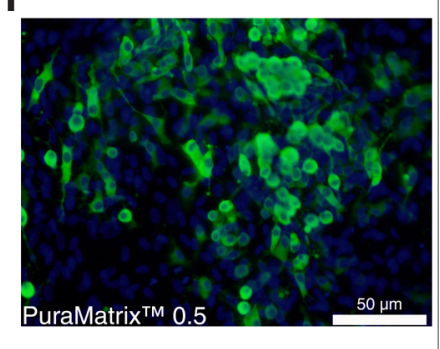

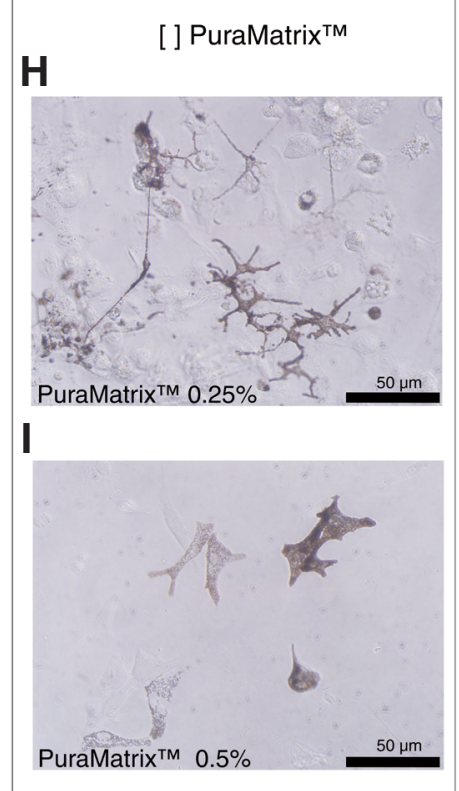

Fig. 2. PuraMatrix ${ }^{\mathrm{TM}}$ (PM) supports differentiation of neural phenotypes in trunk neural crest cell (TNCC) cultures. Frequency of wells containing glial cells (A), adrenergic cells (D) and melanocytes (G) in d14 TNCCs cultures grown on different PM concentrations with or without mesenchymal differentiation factors MDF see Materials and Methods), expressed as $\%$ of the total number of wells containing each phenotype. White bars indicate cultures not treated with MDF, and black bars indicate MDF-treated cultures. Data obtained from 36 culture wells from six independent experiments (to $0.15 \%$ and 0.25 PM) or four independent experiments to $0.5 \%$ $P M$. All analysis performed by $X^{2}$ test where ${ }^{*} P<0.01 ;{ }^{*} P<0.001$ and ${ }^{* *} P<0.0001$. Representative images of immunofluorescence to HNK1 for detection of glial cells (red) from MDF-untreated cultures at $P M 0.15 \%$ (B) and PM $0.25 \%$ (C); immunofluorescence to Tyrosine Hydroxylase (TH) at PM $0.5 \%$ to detectadrenergic cells (green) from both MDF-untreated (E) and MDFtreated cultures (F). Melanocytes were identified by the presence of melanin pigment through phase contrast microscopy from MDF-untreated cultures at PM 0.25\% (H) and PM 0.5\% (I). Cell nuclei in (B,C) and (E,F) were detected by staining with DAPI (in blue). (Magnification B, C, E, F, H, I: 400x). [ ] = concentration.
Jahan-Abad et al., 2018). Thus, PM represents a potential option as substrate/scaffold for future cell therapy approaches related to the central and peripheral nervous system.

No differences in melanocytes were observed, either in the percentage of wells or in the quantity of cells among different PM concentrations containing melanin-expressing cells (Fig. $2 \mathrm{G}$ and Table 1, respectively). MDF treatment did not exert any adverse effect on melanocytic differentiation. At lower PM concentrations $(0.15 \%$ and $0.25 \%)$, melanocytes presented a thin and elongated morphology, some cells displayed a very irregular and branched shape (Fig. $2 \mathrm{H}$ ), very similar to that observed when TNCCs were cultivated on the 3D environment of Matrigel $^{\mathrm{TM}}$ (Ramos-Hryb et al., 2013). On the other hand, in PM $0.5 \%$, the cells were flat and more spread out in the substrate (Fig. 2l), similar to that found when cultivated on 2D-Matrigel ${ }^{\mathrm{TM}}$ or in plastic dishes (Ramos-Hryb et al., 2013). To the best of our knowledge, this is the first time that melanocytes have been shown to differentiate in PM substrate. Thus, PM can be employed as substrate to advance future studies related to normal and abnormal melanocytic development, such as melanoma.

In conclusion, PM at lower concentrations (0.15\% and $0.25 \%)$ was shown to be the best condition to support both glial and adrenergic differentiation. MDF promoted a reduction in both the frequency and quantity of glial cells. Adversely, MDF stimulated a slight augment in frequency and quantity of neurons. Melanocytic differentiation was not affected, either by PM concentrations or by MDF treatment.

\section{PuraMatrix ${ }^{T M}$ supports the differentiation of mesenchymal phenotypes derived from TNCCs}

Since TNCCs did not originate mesenchymal derivatives in vivo, we devoted special attention to the characterization of these phenotypes.

PM allowed the differentiation of smooth muscle cells, adipocytes, chondrocytes and osteoblasts/osteocytes. When MDF was added (from day 7 to day 14), the percentage of cultures exhibiting adipocytes and osteocytes augmented, and bone mineralization was detected at day 21 .

Smooth muscle cells $\left(\mathrm{SMA}^{+}\right)$were by far the most abundant cell type observed in our experiments. $\mathrm{SMA}^{+}$cells appeared in 90 to $100 \%$ of all PM concentrations tested (Fig. 3A). The only exception was observed at PM $0.5 \%$ where MDF-treated cultures displayed a huge reduction (around $50 \%$ ) in both frequency and number of SMA ${ }^{+}$cells (Fig. 3A, Table 2). The number of SMA cells progressively augmented in lower PM concentrations (Table 2). Moreover, MDF treatment promoted a reduction in the number of $\mathrm{SMA}^{+}$cells in all PM concentrations tested (Table 2).

Possibly the abundance of this cell type could be explained 

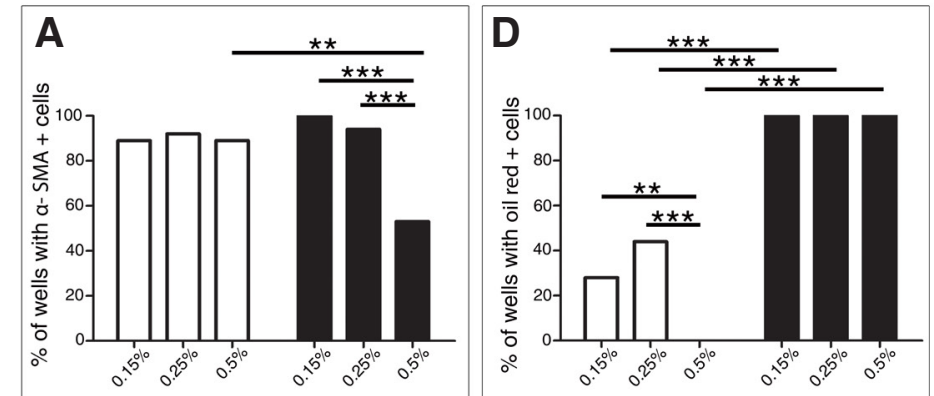

B

[ ] PuraMatrix ${ }^{\mathrm{TM}}$

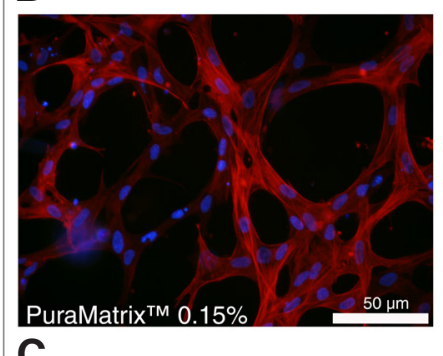

C

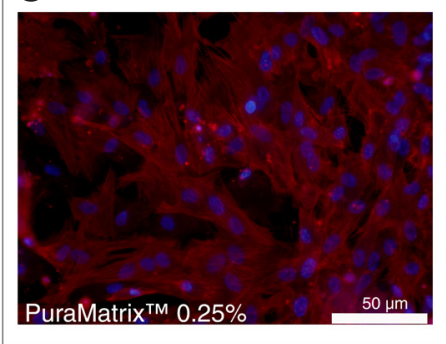

\section{E}

[ ] PuraMatrix ${ }^{\mathrm{TM}}$

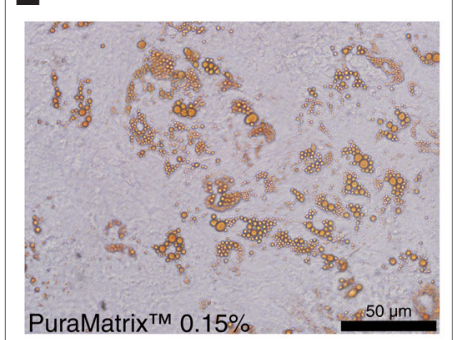

$\mathbf{F}$

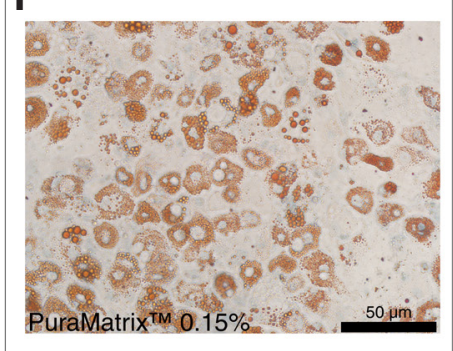

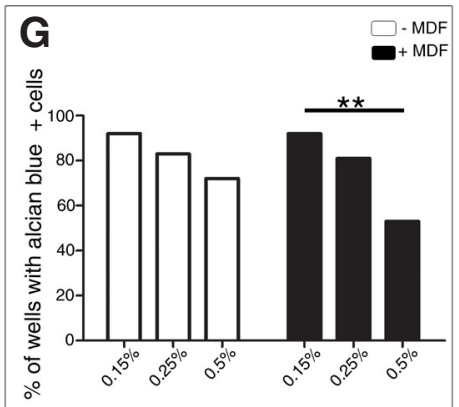

[ ] PuraMatrix ${ }^{\mathrm{TM}}$

H

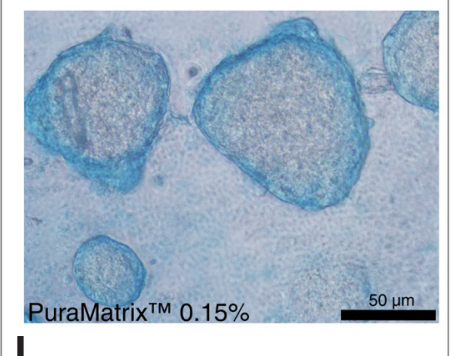

I

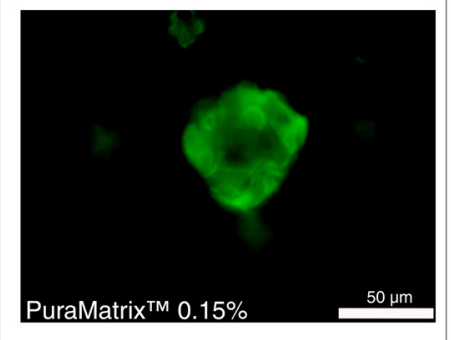

Fig. 3. PuraMatrix ${ }^{\mathrm{TM}}$ (PM) supports differentiation of mesenchymal phenotypes in trunk neural crest cell (TNCC) cultures. Frequency of wells containing smooth muscle cells (A), adipocytes (D), and cartilage nodules (G) in d14 TNCCs cultures grown at different PM concentrations with or without mesenchymal differentiation factors MDF see Materials and Methods), expressed as \% of the total number of wells containing each phenotype. White bars indicate cultures not treated with MDF, and black bars indicate MDF-treated cultures. Data obtained from 36 culture wells from six independent experiments (to $0.15 \%$ and $0.25 \%$ PM) or four independent experiments to $0.5 \%$ PM. All analysis performed by $X^{2}$ test where ${ }^{*} P<0.01$; ${ }^{*} P<0.001$ and ${ }^{* *} P<0.0001$. Representative images of immunofluorescence to smooth muscle actin (SMA) for detection of smooth muscle cells (red) from MDF-untreated cultures at $P M 0.15 \%$ (B) and PM at $0.25 \%$ (C). Representative pictures of phase contrast microscopy displaying adipocytes stained by Oil Red at PM 0.15\% from both MDF-untreated (E) and MDF-treated cultures (F). Representative pictures of phase contrast microscopy displaying cartilage nodules stained by Alcian Blue at PM 0.15\% from MDF-untreated cultures (H) and immunofluorescence to Chondroitin Sulfate at PM 0.15\% from MDF-treated cultures (I). Cell nuclei in (B,C) were detected by staining with DAPI (in blue) (Magnification B, C, E, F, H, I: 400x). [ ] = concentration.

by the similarity between the amino acid sequences of RAD (that forms PM) and the RGD amino acid sequence which allows extensive cell binding through integrin receptors (Zhang et al., 1995). Previously, we elucidated that the extracellular matrix (ECM) protein fibronectin, which contains RGD sequence, promotes the survival of NC progenitors endowed with smooth muscle cell potential (Costa-Silva et al., 2009). Like RGD, RAD motifs allow cell attachment of several cell lines, including fibroblasts and keratinocytes, but RGD-binding integrins are not

\section{TABLE 2}

\section{ESTIMATED AMOUNTS OF MESENCHYMAL PHENOTYPES PER} WELL IN TNCCS CULTURED ON PURAMATRIX' ${ }^{T M}$ (PM)

\begin{tabular}{|c|c|c|c|c|c|c|c|c|}
\hline \multirow[b]{2}{*}{ [ ] $\mathrm{PM}^{\mathrm{TM}}$} & \multicolumn{2}{|c|}{$\begin{array}{c}\text { Smooth } \\
\text { Muscle cells }\end{array}$} & \multicolumn{2}{|c|}{ Adipocytes } & \multicolumn{2}{|c|}{ Chondrocytes } & \multicolumn{2}{|c|}{ Osteocytes } \\
\hline & -MDF & $+\mathrm{MDF}$ & -MDF & $+\mathrm{MDF}$ & -MDF & $+\mathrm{MDF}$ & $-M D F$ & $+\mathrm{MDF}$ \\
\hline $0.15 \%$ & 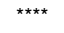 & *** & * & ** & * & * & * & * \\
\hline $0.25 \%$ & *** & ** & * & ** & * & * & N.T & N.T \\
\hline $0.5 \%$ & ** & * & N.D & * & * & * & N.T & N.T \\
\hline
\end{tabular}

Four main groups classified according to the estimated quantity of each phenotype: Small $\left({ }^{*}\right)$, medium $\left({ }^{\star \star}\right)$, large $\left({ }^{\star \star \star}\right)$ and very large quantity $\left({ }^{\star \star \star \star}\right) .{ }^{*}$ Small (present in up to $25 \%$ of the well), ${ }^{\star \star}$ medium (present in up to $50 \%$ of the well), ${ }^{* * *}$ large (present in up to $75 \%$ of the well) and ${ }^{* \star * *}$ very large (present in up to $100 \%$ of the well). N.D. (Not Detected), N.T. (Not Tested). [ ] = concentration. required for cell attachment to PM (Zhang et al., 1995; Holmes et al., 2000;). Thus, it is possible that the interactions between RAD-charged amino acid residues and cell-surface components play a role in non-integrin-mediated cell attachment (Zhang et al., 1995). Moreover, the RGD sequence in chicken cytotactin/tenascin can be mutated to RAD without significant loss of cell attachment activity (Prieto et al., 1993).

At $0.15 \%$ PM concentration, the morphology of SMA ${ }^{+}$cells was shown to be more elongated and fusiform (Fig. 3B). At PM 0.25\%, but especially at $0.5 \%$, they were flatter and more spread out (Fig. 3C). Cells are able to penetrate deeper into the matrix and prolong their filopodia since at lower concentrations, PM exhibits larger pores (Ortinau et al., 2010). On the other hand, increasing concentrations of PM have a denser and tighter composition, forming smaller pores that favor more focal adhesion sites. This can explain the flatter morphology adopted by smooth muscle cells at higher PM concentrations.

Adipocytes were detected in $100 \%$ of wells on all PM concentrations, but only in the presence of MDF (Fig. 3D). MDF promoted an increase not only in the frequency but also in the number of adipocytes (Table 2 and Fig. 3E vs. 3F). Components of MDF like dexamethasone, insulin, isobutylmethylxanthine are known inductors of adipogenesis. For example, 3T3-L1 preadipocytes 
treated for 48 hours with these chemical agents stimulated a sharp increase (20-folds) in the activity of the enzyme fatty acid synthetase, compared to untreated 3T3-L1. The higher level of fatty acid synthetase activity can be attributed entirely to an increased rate of enzyme synthesis promoted by the adipogenic cocktail (Student et al., 1980).

Billon and colleagues showed, for the first time, the ability of both cephalic and trunk NCCs to undergo adipogenesis when stimulated by the same cocktail of hormones and growth factors herein employed. They registered $40 \%$ of the cultures presenting adipocytes (Billon et al., 2007). Moreover, Coelho-Aguiar detected adipocytes in $90 \%$ of TNC mass cultures (400 cells/well seeded) when MDF was added. These cultures were performed on plastic culture wells covered with collagen type I. In clonal cultures (one single cell/well seeded), this frequency drops to $37 \%$. Importantly, adipocytes were not detected in both mass and clonal cultures in the absence of the MDF (Coelho-Aguiar et al., 2013).

Surprisingly, we detected adipocytes in our cultures even without MDF, but only at PM concentrations of $0.15 \%$ and $0.25 \%(28 \%$ and $44 \%$, respectively). Thus, our data show that adipogenic potential of TNCCs can be unveiled only by employing PM as substrate without the necessity of any other stimulant. As hydrogels are softer substrates compared to the plastic cell dishes commonly employed in cultures, some phenomena, such as mechanotransduction, can be related to the spontaneous appearance of this cell type on PM. For example, human MSCs are more likely to differentiate in adipocytes when grown on polyacrylamide gels with low stiffness, in comparison with stiffer matrices (Winer et al., 2009). Considering that increasing concentrations of PM have a denser and tighter composition (Ortinau et al., 2010), the presence of adipocytes only in the lower PM concentrations ( 0.15 and $0.25 \%)$ strengthens this hypothesis.

To the best of our knowledge, this is the first time that PM has been used to obtain adipocytes from NCCs. However, other studies have already used PM as substrate for adipocytes from other sources. For example, adipose stem cells (ASC) from rats were successfully cultured on PM (Yang et al., 2018). Another study performed fat grafts between rats comparing $\mathrm{PM}$ and Matrige $\mathrm{I}^{\mathrm{TM}}$ as substrates to carry adipocytes. The relative presence of intact adipocytes was markedly augmented in the fat/Matrigel ${ }^{\mathrm{TM}}$ graft group (70\%) compared to only $7 \%$ fat/PM grafts (PIASECKI et al., 2008).

In order to improve PM capacities, several short bioactive peptide motifs that act as soluble growth factor analogues and macromolecules of ECM are being conjugated to the C-terminus of amino acids that constitute PM. These "modified" or "functionalized" PMs aim at the development of approaches for a wide range of medical applications for regenerative medicine.

Thus, Liu and colleagues extended the C-terminus of RADA16I (PM) to obtain three different functionalized PMs using: a) the short bone marrow homing motif (SKPPGTSS), b) the heparinbinding motif (FHRRIKA) and c) the two-unit RGD cell adhesion motif (PRGDSGYRGDS). Human adipose stem cells (hASC) were cultured on these new 3-D scaffolds and exhibited higher proliferation, migration and secretion of angiogenic growth factors compared to cells cultured on plastic or pure RADA16-I substrates (Liu et al., 2013).

In conclusion, our observation that PM is able per se to allow, or even promote, adipogenic differentiation from TNCCs should advance NC studies regarding this cell type, especially considering the possibility of using functionalized PM lattices.

Regarding chondrocytes, at 14-day cultures, all PM concentrations tested allowed for the appearance of cartilage nodules as assessed through glycosaminoglycans (GAGs) expression by Alcian Blue staining and Chondroitin Sulfate (CS) immunodetection (Figs. $3 \mathrm{H}-\mathrm{I}$, respectively). Chondrocytes were arranged in both tight and loose nodules. At the center of the tight nodules, GAGs expression was faint, but at their periphery, high levels were detected as assessed by Alcian Blue staining (Fig. $3 \mathrm{H}$ ). On the other hand, chondrocytes present in loose cartilage nodules expressed high levels of CS without distinction between the center and the periphery (Fig. 3I). Possibly, the access of the stain and/or antibody to the core of cartilage nodules is different between dense and loose cell aggregates. GAGs contents must be easier to detect in the periphery of nodules or in loose cell associations owing to the larger space among cells allowing higher ECM deposits. Besides, Wang and colleagues showed that GAG synthesis by bovine articular chondrocytes cultured on PM increased significantly only after day 7. The authors suggested that chondrocytes need to be cultured on PM for more than 14 days for the production of ECM (Wang et al., 2010). Since our cultures started with completely undifferentiated NC cells, it is likely that the time should be extended for large amounts of GAG production and deposition. Another study showed that human chondrocytes (from auricular cartilage) soaked in PM exhibited a significantly smaller accumulation of collagen type II and GAG, compared to cells cultured on atelopeptide collagen and alginate (Yamaoka et al., 2006). However, compared to other hydrogels (Mathixhyal $\AA^{\circ}$, Extrace $\mid \AA$ and Pluronic-Collagen), it is noteworthy that only chondrocytes cultivated in PM exhibit a disaccharide profile which closely matched that of native articular cartilage, as assessed by fluorophore-assisted carbohydrate electrophoresis (FACE) (Wang et al., 2010).

It should be noted that the mesenchymal differentiation media added from day 7 to day 14 or 21 was composed of a cocktail of hormones and growth factors aimed mainly to stimulate adipogenesis and osteogenesis. However, some chemical agents present in the cocktail (i.e. insulin, dexamethasone and ascorbic acid) are also known to stimulate chondrogenesis (Quarto et al., 1992). Increased rates of chondrogenesis were not detected in cultures treated with MDF, probably due to the fact that we placed the MDF just after the period of highest appearance of the cartilage nodules that occurs between the fifth and seventh day of culture.

On day 21, the expression of chondroitin sulfate was very high only in chondrocytes of loose cartilage nodules (Fig. 5F), vanishing from tight nodules, which exhibited high expression of the osteogenic markers Alizarin Red (Fig. 5 B-C) and Alkaline Phosphatase (Fig. 5E). These results reinforce the idea that two different types of cartilage may have developed in our cultures, as represented by tight and loose cell aggregates. The possibility that chondrocytes forming tight nodules transdifferentiate directly into osteoblasts cannot be discarded since several recent studies show that cartilage can transdifferentiate directly into bone, both in vivo and in vitro (Aghajanian and Mohan, 2018). Our studies must address this question appropriately in the future.

Lower PM concentrations $(0.15 \%$ and $0.25 \%)$ exhibit the highest frequencies of wells (80-90\%) containing cartilage nodules, regardless of MDF treatment (Fig. 3G). The only significant reduction (around $50 \%$ ) in the frequency of chondrocyte appearance was 
detected in MDF-treated cultures of $0.5 \%$ compared to $0.15 \%$ PM. Previously, our group demonstrated that Matrigel ${ }^{\mathrm{TM}}$ can support chondrogenic differentiation up to $80 \%$ of TNCCs cultures (RamosHryb et al., 2013). Unfortunately, the number of cartilage nodules obtained on Matrige ${ }^{\mathrm{TM}}$ was very low and never exceeded more than five (5) nodules per well. Here, despite enormous variability, the number of cartilage nodules obtained could easily exceed fifty (50) nodules per well, even in MDF-treated cultures of PM at $0.5 \%$.

Kisiday and colleagues were one of the first research groups to employ PM as substrate to cultivate chondrocytes (Kisiday et al., 2002). Curiously, the same PM employed in our experiments (RADA16) did not present optimal results because it is mechanically rather weak. On this account, the group designed a new self-assembled peptide called KLD12 (n-KLDLKLDLKLDL-c). After 4 weeks of culture, the chondrocytes seeded within the peptide scaffold developed a cartilage-like extracellular matrix rich in proteoglycans and type II collagen. Regrettably, KLD12 is not available commercially.

Other groups tested RADA16 as scaffold or carrier of human mesenchymal stem cells (hMSCs), intending future transplantations to cartilage regeneration. For example, in one study, the nucleus pulposus of intervertebral discs of minipigs was aspirated, and then hMSCs were transplanted in a mixture with PM hydrogels. The hMSCs survived after transplantation into injured porcine spinal disc for at least 6 months and expressed the chondrogenic markers SOX9, Aggrecan, and Collagen IIB (Henriksson et al., 2009). More recently, a new "functionalized" PM called RADAKPSS, constructed by conjugating BMP-7 short active fragment -KPSS- to the C-terminus of RADA16, was employed as substrate to cultivate chondrocytes derived from nucleus pulposus of human donors. The RADA-KPSS peptide attenuated the expression of MMP-3, MMP-9, and ADAMTS-4, promoted the accumulation of ECM proteins, and increased the secretion of GAG, as compared with unmodified RADA16 ( $\mathrm{Li}$ et al., 2018). Another modification of hydrogels includes adsorbing growth factors in PM. Increased proteoglycan synthesis was detected in chondrocytes in cartilage explants placed next to $P M$ hydrogel where heparin-binding insulinlike growth factor 1 (HB-IGF-1) was adsorbed (Florine et al., 2015). These examples show that "modified" or "functionalized" PMs are better than simple PM and represent a promising technique to aid cartilage repair via enhanced matrix production and integration with native tissue.

Finally, we also detected osteoblasts and osteocytes after 14 and 21 days of culture. Unfortunately, it is technically impossible to perform in situ hybridization in PM. The matrix easily dissociates with methanol during the fixation process. Consequently, we could not use the mRNA of Runx2 as an osteoblast marker, as previously described for both cephalic and trunk neural crest (Calloni et al., 2009; Coelho-Aguiar et al., 2013). Besides, the Runx2 antibodies tested did not give us trustworthy results. Thus, we employed the antibody SB5 developed by Arnold Caplan in the 90s to recognize bone specifically in avian species (Bruder and Caplan, 1990).

Around $20 \%$ of cultures exhibited $\mathrm{SB}^{+}$cells at 14 days with PM $0.15 \%$. Although statistically similar, the frequency of culture wells exhibiting SB5+ cells increased three-fold (60\%) upon osteogenic cocktail (MDF) treatment (Fig. 4A). In TNCC cultures performed on PM $0.25 \%$, around $60 \%$ of culture wells displayed $\mathrm{SB}^{+}$cells. After MDF treatment, this frequency rose to $100 \%$ (Fig. 4A). Taken together, these data show that higher PM concentration and MDF treatment (as expected) stimulate osteogenesis.

On 21 days of culture (analyzed only on PM $0.15 \%$ ), both alizarin red (AR) (Fig. 5B) and ALP staining were present in MDF-untreated cultures (around $40 \%$ for both markers), showing that bone mineralization takes place even in the absence of an osteogenic cocktail (Figs. 5 A,D). However, TNCCs cultures treated with MDF displayed higher rates of bone mineralization compared to untreated cultures, whereas $100 \%$ of culture wells showed AR staining (Figs. $5 \mathrm{~A}, \mathrm{C}$ ) and $80 \%$ of wells exhibited ALP expression (Figs. $5 \mathrm{D}, \mathrm{E}$ ). The fact that $\mathrm{PM}$ per se has the capacity to allow osteogenesis was already demonstrated by growing human mesenchymal stem cells (MSC) on $0.25 \%$ PM without the addition of any osteogenic-promoting cocktail (Chen et al., 2013). However, as observed here, the employment of an osteogenic medium stimulates the increase of ALP production by MSCs (derived from rat bone marrow) encapsulated in PM (Hamada et al., 2008). Increased ALP expression was also detected in an osteoblastic cell line (HMS0014) when cultivated in PM 1\% and treated with an osteogenic cocktail (IWAl et al., 2012). Tenenbaum was the first to establish two completely defined mediums to optimize the bone-formation process similar to the ossification process observed

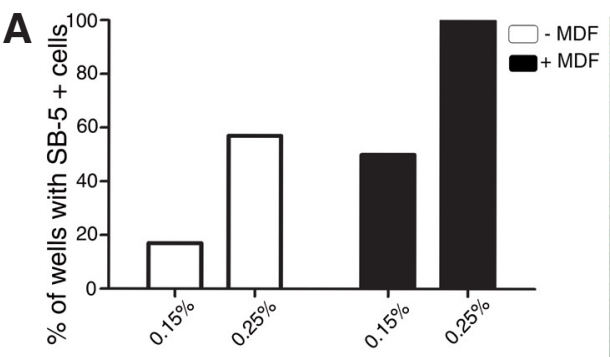

[ ] PuraMatrix ${ }^{\mathrm{TM}}$

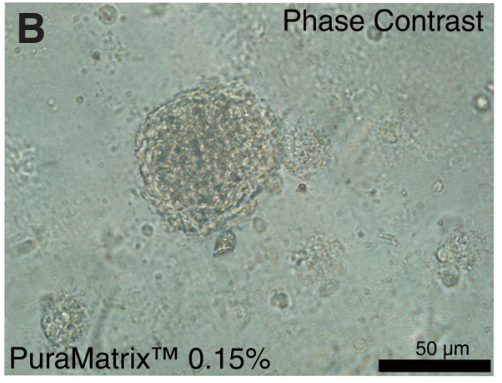

PuraMatrix ${ }^{\mathrm{TM}} 0.15 \%$

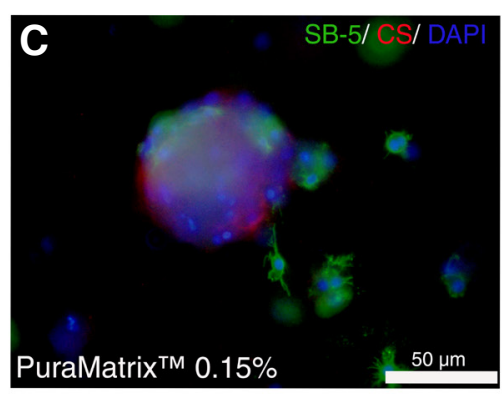

Fig. 4. PuraMatrix ${ }^{\mathrm{TM}}$ (PM) supports the differentiation of osteoblasts in 14d trunk neural crest cell (TNCC) cultures. The phenotypic analysis of osteoblasts was performed in $14 d$ cultures on PM at $0.15 \%$ and $0.25 \%$ submitted, or not, to mesenchymal differentiation media (MDF). Frequency of culture wells expressed as \% of the total number of wells containing cells immunoreactive to SB5. White bars indicate cultures not treated with MDF, and black bars indicate MDF-treated cultures (A). Data obtained from 12 culture wells of four independent experiments to $0.15 \%$ PM and from 7 culture wells of two independent experiments to $0.25 \%$ PM. All analysis by $X^{2}$ where ${ }^{*} P<0.01 ;{ }^{*} P<0.001$ and ${ }^{*} * P<0.0001$. Phase contrast image revealing a cell aggregate at PM $0.15 \%$ (B) and the same cell aggregate analyzed through immunoreactivity to SB-5 (green) and to Chondroitin Sulfate (CS, red) for detection of osteoblasts and chondrocytes, respectively. Cell nuclei were detected by staining with DAPI (in blue) (C). (Magnification B and $\mathrm{C}:$ 400x). [ ] = concentration. 
in vivo (Tenenbaum and Heersche, 1982). Both mediums were supplemented with $\beta$-glycerol phosphate. The rationale for using this reagent is to supply the culture system with an additional source of organic phosphate ions equivalent to that observed in physiological conditions. The phosphate ions should be made available in places where alkaline phosphatase is present, thereby reducing the possibility of non-specific mineral precipitation. The localization of the mineral and the presence of a clear border between mineralized and non-mineralized areas show that a controlled mineralization process is operating within the system (Tenenbaum and Heersche, 1982). Mineralization of bone nodules occurs in two phases, an initiation phase and a progression phase. $\beta$-glycerol phosphate is absolutely necessary at the initiation phase to trigger ALP activity. ALP is essential to start the initiation, but not the progression of mineralization (Bellows et al., 1991).

Our data shows that mineralization process occurred in cellular aggregates with borders clearly distinguishable between the mineralized and non-mineralized areas. We can see in Figs. 5 E-F that nodules $\mathrm{ALP}^{+}$were completely negative for Chondroitin Sulfate (CS) immunostaining, showing the clear distinction between cartilage and bone. Not surprisingly, ALP also colocalizes with alizarin red staining in some regions of bone nodules (Fig. 5C, black arrows). In cultures untreated with MDF, alcian blue staining persisted but was very faint and discrete at the periphery of some alizarin red stained nodules suggesting the possibility that chondrocytes can transdifferentiate directly into osteoblasts, as already mentioned (Fig. 5B, white arrow).

Although our study is the first to show that PM supports the differentiation of osteoblast/osteocyte from embryonic NCCs, a previous study had already detected this phenotype when fibroblasts derived from periodontal ligament, a tissue of $\mathrm{NC}$ origin, were cultured at PM $1 \%$ and $0.5 \%$ concentrations. It is noted that periodontal ligament fibroblast-like cells differentiate not only into osteoblastic but also into vascular cell lineages. These data clearly show the existence/maintenance of a multipotent adult cell population that constitutes an interesting source of stem cells; thus, PM can be employed to allow the differentiation of NC phenotypes rarely obtained using other kinds of substrates (Shirai et al., 2009).

In 2002, Anthony Graham and Imelda McGonnell were the first to demonstrate the skeletogenic potential of TNCCs (McGonnell and Graham, 2002). In the following year, Abzhanov and colleagues suggested that the ability of TNCCs cultures to adopt chondrogenic fates may be due to the loss or downregulation of HOX gene expression in a subset of cells (Abzhanov et al., 2003). The skeletogenic ability of anterior-most CNCCs is well known to be related to the absence of $H O X$ gene expression. In this article, we do not explore whether PM constitutes an environment that promotes the downregulation of HOXgenes in TNCCs. This is an exciting possibility and the next steps of our research group should be in this direction.

Although TNCCs are unable to originate skeletogenic phenotypes in vivo in birds and mammals, evidence shows that the fossils of extinct fishes that lived from 470 to 370 million years ago were endowed with an ossified integument armor in which one of its constitutive elements is the protein dentin, a marker for the NC origin of calcified tissues (SMITH, 1991). The evidence of this ancestral contribution of TNCCs to skeletogenic tissues can be detected in extant animals. For example, Scott Gilbert's group showed that the turtle plastron bones originate from a late-emigrating NC population derived from trunk TNC (Cebra-Thomas et al., 2013). More recently, it has been demonstrated that TNCCs also give rise to odontoblasts of trunk dermal denticles in a cartilaginous fish, the little skate (Leucoraja erinacea) (Gillis et al., 2017). The data here described reinforce the importance of these findings.

Considering that $\mathrm{PM}$ is an excellent environment to obtain skeletogenic cell types, we can conceive a scenario where physical properties of this substrate, through mechanotransduction, can elicit epigenetic processes controlling gene expression (like $\mathrm{HOX}$
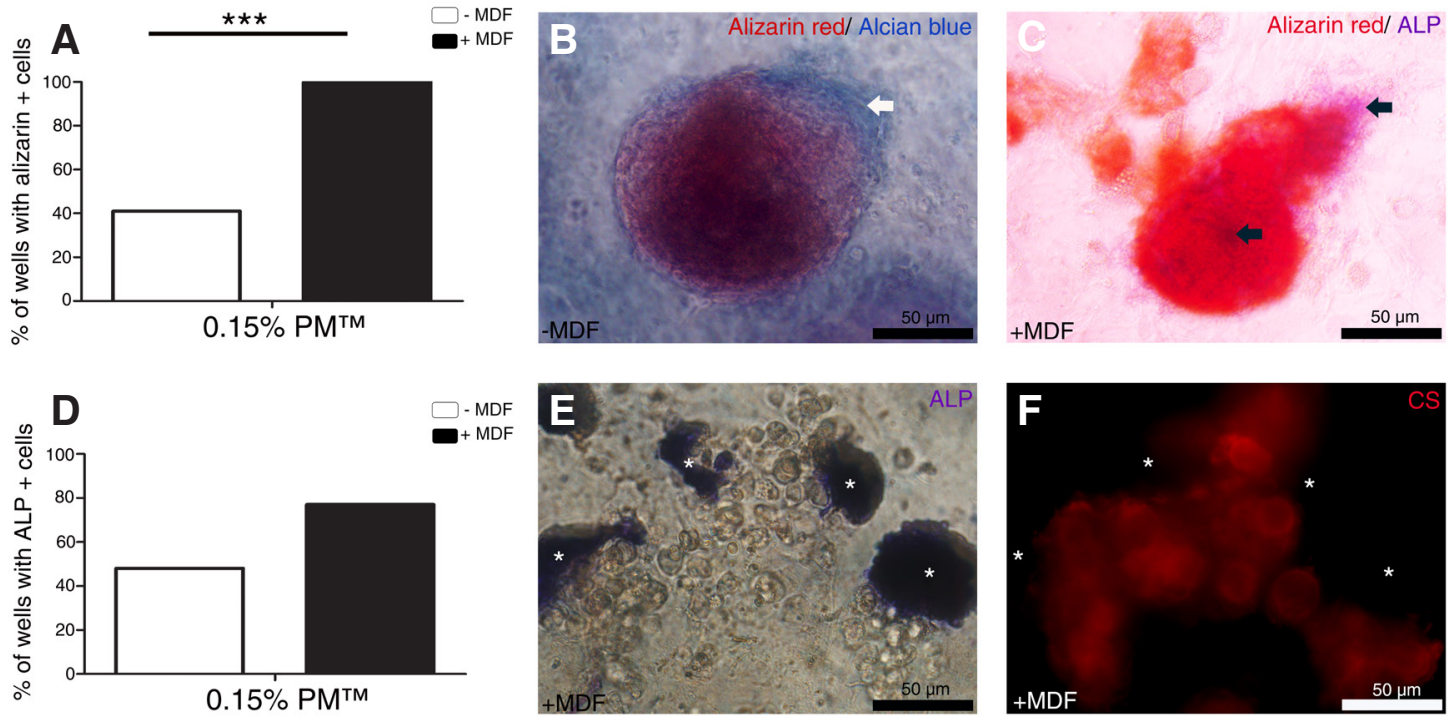

Fig. 5. PuraMatrix ${ }^{\mathrm{TM}}$ (PM) supports the differentiation of osteocytes in $21 d$ trunk neural crest cell (TNCC) cultures. TNCCs cultures were performed on PM $0.15 \%$ treated or not with MDF from d7 to d21. Frequency of wells expressed as \% of the total number of wells containing cell aggregates stained by Alizarin Red (A) and Alkaline Phosphatase(D) assessedat d21. White bars indicate cultures not treated with MDF, and black bars indicate MDFtreated cultures. For Alizarin Red, the data were obtained from 17 untreated MDF and 19 MDF-treated wells. For Alkaline Phosphatase, data were obtained from 23 untreated MDF and 22 MDF-treated wells. All data obtained from four independent experiments. All analysis performed by $X^{2}$ where ${ }^{*} P<0.01 ;{ }^{*} P<0.001$ and ${ }^{*} * P<0.0001$. Microscopic views of cell aggregates stained by Alizarin Red (red) and Alcian Blue (white arrow) in untreated MDF cultures (B) Alizarin Red (red) and Alkaline Phosphatase (black arrows) staining in MDF-treated cultures (C). Phase contrast microscopy showing Alkaline Phosphatase-stained cell aggregates (dark violet indicated by white asterisks in E), around chondrocytes (round bright cells) assessed by Chondroitin Sulfate (CS) immunolabeling (red in F). Cell nuclei were detected by staining with DAPI (in blue). Magnification: B-C; E-F: 400x. 
downregulation), which allow dormant mesenchymal potentialities of TNCCs to emerge. Thus, PM can be useful to deepen the knowledge of exciting developmental biology studies.

Moreover, the fact that different adult tissues contain a reservoir of NCCs behaving as an embryonic structure allows us to imagine endless possibilities of biotechnological approaches aimed at tissue regeneration employing NCCs as the cellular source for a review see Dupin and Coelho-Aguiar, 2013; Gonçalves Trentin and Wosgrau Calloni, 2013). The right kind of cells employed for tissue regeneration is just part of the equation when it comes to tissue regeneration. Equally important is the scaffold to cultivate, maintain and also transplant the cells to the site of injury. In this sense, PM, together with all its derivations, whether "modified" or "functionalized", constitutes an excellent system for future biotechnological approaches and studies related to stem cell multipotentiality and differentiation.

\section{Acknowledgments}

The authors would like to thank the LCME-UFSC and LAMEB-UFSC for technical support and for providing their respective infrastructure for carrying out some of the experimental tests. This work was supported by the Ministério da Ciência e Tecnologia/Conselho Nacional de Desenvolvimento Científico e Tecnológico (MCT/ CNPq/Brazil), Coordenação de Aperfeiçoamento de Pessoal de Nível Superior (CAPES, Brazil), and Fundação de Amparo de Pesquisa do Estado de Santa Catarina (FAPESC, SC, Brazil). Clarissa Reginato Taufer received a fellowship from CAPES.

\section{Declaration of Conflicting Interests}

The author(s) declared no potential conflicts of interest with respect to the research, authorship, commercial relationships, and/or publication of this article.

\section{References}

ABZHANOV A, TZAHOR E, LASSAR AB, TABIN CJ (2003). Dissimilar regulation of cell differentiation in mesencephalic (cranial) and sacral (trunk) neural crest cells in vitro. Development 130: 4567-4579.

AGHAJANIAN P, MOHAN S (2018). The art of building bone: Emerging role of chondrocyte-to-osteoblast transdifferentiation in endochondral ossification. Bone Res6.

BAGGIOLINI A, VARUM S, MATEOS JM, BETTOSINI D, JOHN N, BONALLI M, ZIEGLERU, DIMOUL, CLEVERS H, FURRERR, SOMMERL(2015). Premigratory and migratory neural crest cells are multipotent in vivo. Cell Stem Cell16:314-322.

BAROFFIO A, DUPIN E, LE DOUARIN NM (1988). Clone-forming ability and differentiation potential of migratory neural crest cells. Proc Natl Acad Sci USA 85: 5325-5329

BAROFFIOA, DUPINE, LE DOUARIN NM (1991). Common precursors for neural and mesectodermal derivatives in the cephalic neural crest. Development 112:301-5.

BELLOWS CG, AUBIN JE, HEERSCHE JNM (1991). Initiation and progression of mineralization of bone nodules formed in vitro: the role of alkaline phosphatase and organic phosphate. Bone Miner 14: 27-40.

BILLON N, IANNARELLIP, MONTEIRO MC, GLAVIEUX-PARDANAUD C, RICHARDSON WD, KESSARIS N, DANI C, DUPIN E (2007). The generation of adipocytes by the neural crest. Development 134: 2283-92.

BITTENCOURT DA, DA COSTA MC, CALLONI GW, ALVAREZ-SILVA M, TRENTIN AG (2013). Fibroblast growth factor 2 promotes the self-renewal of bipotent glial smooth muscle neural crest progenitors. Stem Cells Dev 22: 1241-1251.

BRONNER-FRASER M, FRASER SE (1988). Cell lineage analysis reveals multipotency of some avian neural crest cells. Nature 335: 161-4.

BRUDER SP, CAPLAN AI (1990). Terminal differentiation of osteogenic cells in the embryonic chick tibia is revealed by a monoclonal antibody against osteocytes. Bone 11: 189-198.

CALLONI GW, LE DOUARIN NM, DUPIN E (2009). High frequency of cephalic neural crest cells shows coexistence of neurogenic, melanogenic, and osteogenic dif- ferentiation capacities. Proc Natl Acad Sci USA 106: 8947-8952.

CALLONI GW, GLAVIEUX-PARDANAUD C, LE DOUARIN NM, DUPIN E (2007) Sonic Hedgehog promotes the development of multipotent neural crest progenitors endowed with both mesenchymal and neural potentials. Proc Natl Acad Sci USA 104: 19879-19884.

CEBRA-THOMAS JA, TERRELLA, BRANYANK, SHAHS, RICE R, GYIL, YIN M, HU Y, MANGAT G, SIMONET J, BETTERS E, GILBERT SF (2013). Late-emigrating trunkneural crest cells in turtle embryos generate an osteogenic ectomesenchyme in the plastron. Dev Dyn 242: 1223-1235.

CHEN J, SHI ZD, JI X, MORALES J, ZHANG J, KAUR N, WANG S (2013). Enhanced osteogenesis of human mesenchymal stem cells by periodic heat shock in selfassembling peptide hydrogel. Tissue Eng - Part A 19: 716-728.

COELHO-AGUIAR JM, LE DOUARIN NM, DUPIN E (2013). Environmental factors unveil dormant developmental capacities in multipotent progenitors of the trunk neural crest. Dev Biol 384: 13-25.

COSTA-SILVA B, DA COSTA MC, MELO FR, NEVES CM, ALVAREZ-SILVA M, CALLONI GW, TRENTINAG (2009). Fibronectin promotes differentiation of neural crest progenitors endowed with smooth muscle cell potential. Exp Cell Res315: 955-967.

DA COSTA MC, TRENTIN AG, CALLONI GW (2018). FGF8 and Shh promote the survival and maintenance of multipotent neural crest progenitors. Mech Dev 154: 251-258.

DUPIN E, CALLONI GW, COELHO-AGUIAR JM, LEDOUARIN NM (2018). The issue of the multipotency of the neural crest cells. Dev Biol 444: S47-S59.

DUPIN E, COELHO-AGUIAR JM (2013). Isolation and differentiation properties of neural crest stem cells. Cytometry A 83: 38-47.

FLORINE EM, MILLER RE, LIEBESNY PH, MROSZCZYK KA, LEE RT, PATWARI $P$, GRODZINSKY AJ (2015). Delivering heparin-binding insulin-like growth factor 1 with self-assembling peptide hydrogels. Tissue Eng - Part A 21: 637-646.

GEORGEEL, GEORGES-LABOUESSEEN, PATEL-KING RS, RAYBURN H, HYNES RO (1993). Defects in mesoderm, neural tube and vascular development in mouse embryos lacking fibronectin. Development 119: 1079-1091.

GILLIS JA, ALSEMA EC, CRISWELL KE (2017). Trunk neural crest origin of dermal denticles in a cartilaginous fish. Proc Natl Acad Sci USA 18: 201713827.

GONÇALVESTRENTINA, WOSGRAU CALLONI G (2013). The Neural Crest and the Stem Cells of Neural Crest. In Resident Stem Cells and Regenerative Therapy (Eds R dos Santos Goldenberg and A Campos de Carvalho). Elsevier Inc., pp. 157-176.

HAMADA K, HIROSE M, YAMASHITA T, OHGUSHI H (2008). Spatial distribution of mineralized bone matrix produced by marrow mesenchymal stem cells in selfassembling peptide hydrogel scaffold. J Biomed Mater Res Part A 84A: 128-136.

HENRIKSSON HB, SVANVIK T, JONSSON M, SCI LM, HAGMAN M, HORN M, LINDAHL A, BRISBY H (2009). Transplantation of Human Mesenchymal Stems Cells Into. Spine J 34: 141-148.

HOLMES TC, DE LACALLE S, SU X, LIU G, RICH A, ZHANG S (2000). Extensive neurite outgrowth and active synapse formation on self-assembling peptide scaffolds. Proc Natl Acad Sci USA 97: 6728-6733.

IWAI Y, MATSUDA Y, NAKATSUKA M, MIKAMI Y, KUMABE S (2012). A preliminary study of the dental implant therapy-initial osteogenesis of Human Mesenchymal Stem (HMS0014) cells on titanium discs with different surface modifications-. Okajimas Folia Anat Jpn 88: 133-140.

JAHANBAZI JAHAN-ABAD A, SAHAB NEGAHS, HOSSEINI RAVANDI H, GHASEM S, BORHANI-HAGHIGHI M, STUMMER W, GORJI A, KHALEGHI GHADIRI M (2018). Human Neural Stem/Progenitor Cells Derived From Epileptic Human Brain in a Self-Assembling Peptide Nanoscaffold Improve Traumatic Brain Injury in Rats. Mol Neurobiol 55: 9122-9138.

KANEKO A, SANKAI Y (2014). Long-Term Culture of Rat Hippocampal Neurons at Low Density in Serum-Free Medium: Combination of the Sandwich Culture Technique with the Three-Dimensional Nanofibrous Hydrogel PuraMatrix Ed. K Hoyt. PLoS One 9: e102703.

KISIDAY J, JIN M, KURZ B, HUNG H, SEMINO C, ZHANG S, GRODZINSKY a J (2002). Self-assembling peptide hydrogel fosters chondrocyte extracellular matrix production and cell division: Implications for cartilage tissue repair. Proc Natl Acad Sci USA 99: 9996-10001.

KLEINMAN HK, MARTIN GR (2005). Matrigel: Basement membrane matrix with biological activity. Semin Cancer Biol 15: 378-386.

LI X, CHENG S, WU Y, YING J, WANG C, WEN T, BAI X, JI W, WANG D, RUAN D 
(2018). Functional self-assembled peptide scaffold inhibits tumor necrosis factoralpha-induced inflammation and apoptosis in nucleus pulposus cells by suppressing nuclear factor-kB signaling. J Biomed Mater Res Part A 106: 1082-1091.

LIU X, WANG Xiumei, WANG Xiujuan, REN H, HE J, QIAO L, CUI FZ (2013). Functionalized self-assembling peptide nanofiber hydrogels mimic stem cell niche to control human adipose stem cell behavior in vitro. Acta Biomater 9: 6798-6805.

LORINGJ, GLIMELIUSB, WESTONJA(1982). Extracellular matrix materials influence quail neural crest cell differentiation in vitro. Dev Biol 90: 165-174

MCGONNELL IM, GRAHAMA(2002). Trunk Neural Crest Has Skeletogenic Potential. Curr Biol 12: 767-771.

MORADI F, BAHKTIARI M, JOGHATAEI MT, NOBAKHT M, SOLEIMANI M, HASANZADEH G, FALLAH A, ZARBAKHSH S, HEJAZIAN LB, SHIRMOHAMMADI M, MALEKIF (2012). BD PuraMatrix peptide hydrogel as a culture system for human fetal Schwann cells in spinal cord regeneration. J Neurosci Res 90: 2335-2348.

NUNE M, SUBRAMANIAN A, KRISHNAN UM, SETHURAMAN S (2019). Peptide nanostructures on nanofibers for peripheral nerve regeneration. $J$ Tissue Eng Regen Med 13: 1059-1070.

ORTINAU S, SCHMICH J, BLOCK S, LIEDMANN A, JONAS L, WEISS DG, HELM CA, ROLFS A, FRECH MJ (2010). Effect of 3D-scaffold formation on differentiation and survival in human neural progenitor cells. Biomed Eng Online 9: 1-18.

PARATORE C, HAGEDORN L, FLORIS J, HARI L, KLÉBER M, SUTER U, SOMMER $L$ (2002). Cell-intrinsic and cell-extrinsic cues regulating lineage decisions in multipotent neural crest-derived progenitor cells. Int J Dev Biol 46: 193-200.

PERRIS R, SYFRIG J, PAULSSON M, BRONNER-FRASER M (1993). Molecular mechanisms of neural crest cell attachment and migration on types I and IV collagen. J Cell Sci 106: 1357-1368.

PIASECKI J, MORENO K, GUTOWSKI K (2008). Beyond the Cells: Scaffold Matrix Character Affects the In vivo Performance of Purified Adipocyte Fat Grafts. Aesthetic Surg J 28: 306-312.

PRIETO AL, EDELMAN GM, CROSSIN KL (1993). Multiple integrins mediate cell attachment to cytotactin/tenascin. Proc Natl Acad Sci USA 90: 10154-10158.

QUARTO R, CAMPANILE G, CANCEDDA R, DOZIN B (1992). Thyroid hormone, insulin, and glucocorticoids are sufficient to support chondrocyte differentiation to hypertrophy: A serum-free analysis. J Cell Biol 119: 989-995.

RAMOS-HRYB AB, DA-COSTA MC, TRENTIN AG, CALLONI GW (2013). Matrigel supports neural, melanocytic and chondrogenic differentiation of trunk neural crest cells. Int J Dev Biol 57: 853-858.

SHAH NM, ANDERSON DJ (1997). Integration of multiple instructive cues by neural crest stem cells reveals cell-intrinsic biases in relative growth factor responsive- ness. Proc Natl Acad Sci USA 94: 11369-11374.

SHIRAI K, ISHISAKI A, KAKU T, TAMURA M, FURUICHI Y (2009). Multipotency of clonal cells derived from swine periodontal ligament and differential regulation by fibroblast growth factor and bone morphogenetic protein. $J$ Periodontal Res 44: 238-247.

SMITH MM (1991). Putative Skeletal Neural Crest Cells in Early Late Ordovician Vertebrates from Colorado. Science (80-) 251: 301-303.

STUDENT AK, HSU RY, LANET MD (1980). Induction of Fatty Acid Synthetase Synthesis in Differentiating 3T3-LI Preadipocytes*. J Biol Chem 255: 4745-4750.

TENENBAUM HC, HEERSCHE JNM (1982). Differentiation of osteoblasts and formation of mineralized bone in vitro. Calcif Tissue Int 34: 76-79.

THONHOFF JR, LOUDI, JORDAN PM, ZHAOX, WU P (2008). Compatibility of human fetal neural stem cells with hydrogel biomaterials in vitro. Brain Res 1187: 42-51.

TRENTIN A, GLAVIEUX-PARDANAUD C, LE DOUARIN NM, DUPIN E (2004) Self-renewal capacity is a widespread property of various types of neural crest precursor cells. Proc Natl Acad Sci USA 101: 4495-4500.

WANG QG, HUGHES N, CARTMELL SH, KUIPER NJ (2010). The composition of hydrogels for cartilage tissue engineering can influence glycosaminoglycan profiles. Eur Cells Mater 19: 86-95.

WINER JP, JANMEY PA, MCCORMICK ME, FUNAKIM (2009). Bone marrow-derived human mesenchymal stem cells become quiescent on soft substrates but remain responsive to chemical or mechanical stimuli. Tissue Eng - Part A 15: 147-154.

YAMAOKA H, ASATO H, OGASAWARA T, NISHIZAWA S, TAKAHASHI T, NAKATSUKA T, KOSHIMA I, NAKAMURA K, KAWAGUCHI H, CHUNG U, TAKATO T, HOSHIK(2006). Cartilage tissue engineering using human auricular chondrocytes embedded in different hydrogel materials. J Biomed Mater Res Part A78A: 1-11.

YANG H, HONG N, LIU H, WANG J, LI Y, WU S (2018). Differentiated adiposederived stem cell cocultures for bone regeneration in RADA16-I in vitro. J Cell Physiol 233: 9458-9472.

YLÄ-OUTINEN L, JOKI T, VARJOLA M, SKOTTMAN H, NARKILAHTI S (2014) Three-dimensional growth matrix for human embryonic stem cell-derived neuronal cells. J Tissue Eng Regen Med 8: 186-194.

ZHANG S, HOLMES TC, DIPERSIO CM, HYNES RO, SU X, RICH A (1995). Selfcomplementary oligopeptide matrices support mammalian cell attachment. Biomaterials 16: 1385-1393.

ZHANG S, ZHAO X, SPIRIO L (2005). PuraMatrix: Self-Assembling Peptide Nanofiber Scaffolds. In Scaffolding In Tissue Engineering (Eds PX Ma and J Elisseeff). CRC Press, pp. 217-237. 


\section{Further Related Reading, published previously in the Int. J. Dev. Biol.}

Matrigel supports neural, melanocytic and chondrogenic differentiation of trunk neural crest cells Ana B. Ramos-Hryb, Meline C. Da-Costa, Andréa G. Trentin and Giordano W. Calloni*

Int. J. Dev. Biol. 57: 885 - 890 (2013)

doi: $10.1387 / \mathrm{ijdb} .130206 \mathrm{gw}$

A life in Science with the avian embryo

Nicole M. Le Douarin*

Int. J. Dev. Biol. 62: 19 - 33 (2018)

doi: $10.1387 / \mathrm{ijdb} .170287 \mathrm{NL}$

Insights into neural crest development from studies of avian embryos

Shashank Gandhi and Marianne E. Bronner*

Int. J. Dev. Biol. 62: 183 - 194 (2018)

doi: $10.1387 / \mathrm{ijdb} .180038 \mathrm{sg}$

Trunk neural crest cells: formation, migration and beyond

Guillermo A. Vega-lopez, Santiago Cerrizuela and Manuel J. Aybar

Int. J. Dev. Biol. 61: 5 - 15 (2017)

doi: $10.1387 / \mathrm{ijdb} .160408 \mathrm{gv}$

The instability of the neural crest phenotypes: Schwann cells can differentiate into myofibroblasts

Carla Real, Corinne Glavieux-Pardanaud, Pierre Vaigot, Nicole Le Douarin and Elisabeth Dupin* Int. J. Dev. Biol. 49: 151 - 159 (2005)

doi: $10.1387 / \mathrm{ijdb} .041940 \mathrm{cr}$

Regulation of neural crest cell populations: occurrence, distribution and underlying mechanisms

$\mathrm{J} L$ Vaglia and B K Hall

Int. J. Dev. Biol. (1999) 43: 95-110

http://www.intjdevbiol.com/web/paper/10235385

Bone morphogenetic protein 4 promotes craniofacial neural crest induction from human pluripotent stem cells

Sumiyo Mimura, Mika Suga, Kaori Okada, Masaki Kinehara, Hiroki Nikawa and Miho K. Furue Int. J. Dev. Biol. (2016) 60: 21-28

https://doi.org/10.1387/ijdb.160040mk
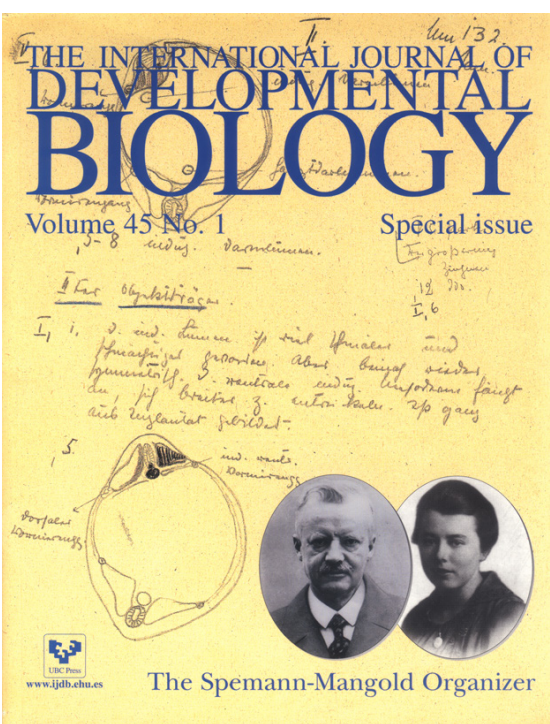

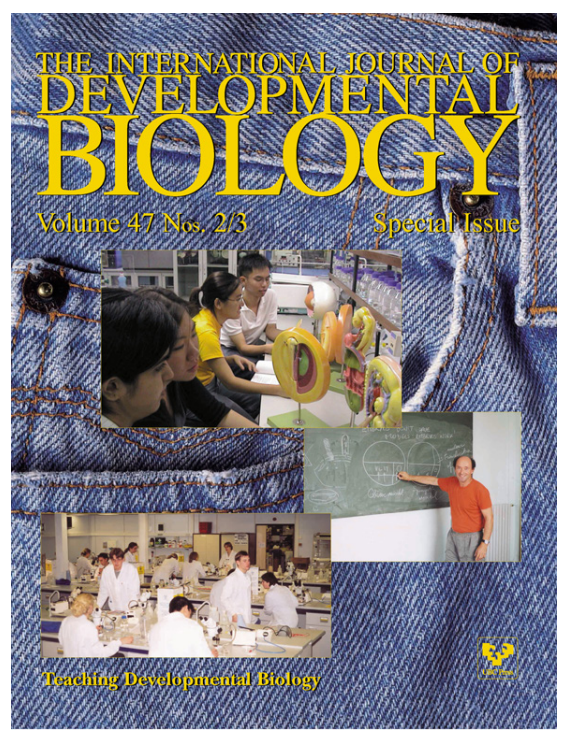

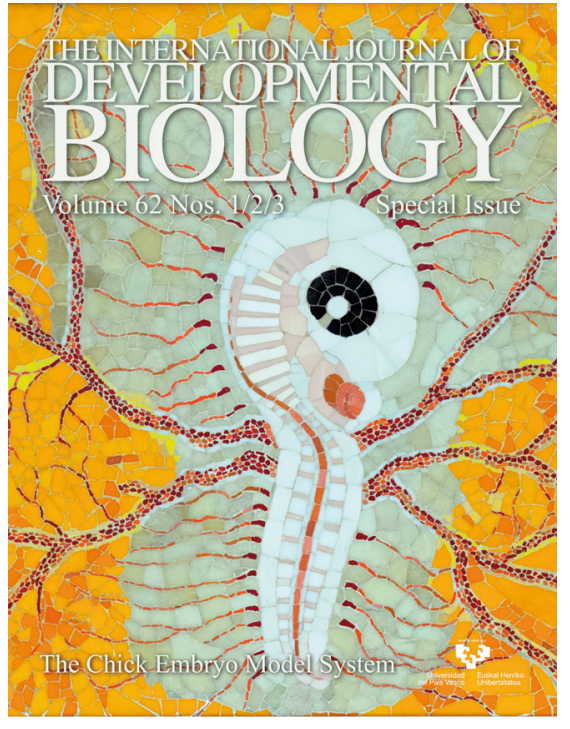

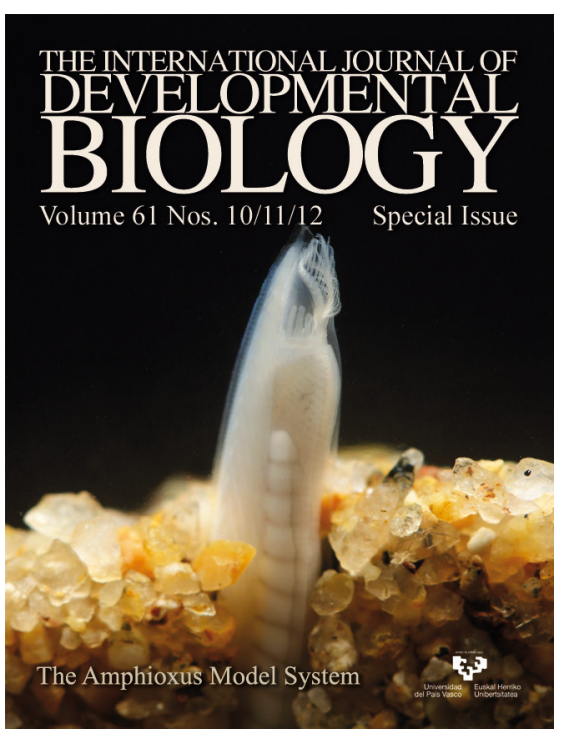

